Zander Kerstin (Orcid ID: 0000-0002-2237-1801)

\title{
Renewal Ecology: Conservation for the Anthropocene
}

Running head: Renewal Ecology

Bowman DMJS', Garnett $\mathrm{ST}^{2}$, Barlow EWR ${ }^{3}$, Bekessy $\mathrm{SA}^{4}$, Bellairs $\mathrm{SM}^{2}$, Bishop MJ $\mathrm{J}^{5}$, Bradstock RA ${ }^{6}$, Jones $\mathrm{DN}^{7}$, Maxwell SL ${ }^{8}$, Pittock $\mathrm{J}^{9}$, Toral-Granda $\mathrm{MV}^{2}$, Watson JEM ${ }^{8,10}$, Wilson $\mathrm{T}^{11}$, Zander $\mathrm{KK}^{11}$, Hughes $\mathrm{L}^{5^{*}}$

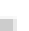

1. School of Biological Sciences, University of Tasmania, Private Bag 55, Hobart, Tasmania 7001, Australia

2. Research Institute for the Environment and Livelihoods, Charles Darwin University, Casuarina, Northern Territory 0909, Australia

3. Faculty of Veterinary and Agricultural Sciences, University of Melbourne, Parkville, Victoria 3011, Australia

4. Interdisciplinary Conservation Science Research Group, School of Global, Urban and Social Studies, RMIT University, GPO Box 2476, Melbourne 3001, Australia

5. Dept. of Biological Sciences, Macquarie University, North Ryde, New South Wales 2109, Australia

6. Centre for Environmental Risk Management of Bushfires, University of Wollongong, New South Wales 2522, Australia

7. Environmental Futures Research Institute, Griffith University, Nathan QLD 4111, Australia

8. School of Earth and Environmental Sciences, The University of Queensland, St Lucia QLD 4072, Australia

9. Fenner School of Environment and Society, The Australian National University, 48 Linnaeus Way, Acton ACT 2600, Australia

This is the author manuscript accepted for publication and has undergone full peer review but has not been through the copyediting, typesetting, pagination and proofreading process, which may lead to differences between this version and the Version of Record. Please cite this article as doi: $10.1111 /$ rec.12560

This article is protected by copyright. All rights reserved. 
11. Northern Institute, Charles Darwin University, Casuarina, NT 0909, Australia

*Corresponding author

\section{Author Contributions}

All authors contributed to the writing of the paper: DMJSB, STG, LH and KKZ lead the writing with case studies drafted by MJB (coasts), RAB (fire-breaks), SAB and DNJ (urban ecology), JP (freshwater and energy), SLM and EWRB (agriculture) and SMB and DMJSB (mines).

\section{Abstract}

The global-scale and rapidity of environmental change is challenging ecologists to re-imagine their theoretical principles and management practices. Increasingly, historical ecological conditions are inadequate targets for restoration ecology, geographically circumscribed nature reserves are incapable of protecting all biodiversity, and the precautionary principle applied to management interventions no longer ensures avoidance of ecological harm. In addition, human responses to global environmental changes, such as migration, building of protective infrastructures, and land use change, are having their own negative environmental impacts. We use examples from wildlands, urban and degraded environments, as well as marine and freshwater ecosystems, to show that human adaptation responses to rapid ecological change can be explicitly designed to benefit biodiversity. This approach, which we call 'renewal ecology', is based on acceptance that environmental change will have transformative effects on coupled human and natural systems and recognizes the need to harmonise biodiversity with human infrastructure, for the benefit of both.

Keywords: social-ecological systems, climate, biodiversity, environmental change, opportunity, innovation

\section{Implications}

i. By accepting environmental change as inevitable and irrevocable, renewal ecology provides those practicing conservation management greater social license to innovate.

This article is protected by copyright. All rights reserved. 
ii. Irretrievably degraded land and seascapes can provide opportunities to renew biological function and diversity, in places where attempts to recreate the former natural state would fail.

iii. Urban and agricultural landscapes largely written off as sites for effective conservation can be re-imagined as species habitat with enhanced ecological functionality, while delivering cobenefits for human wellbeing.

\section{Introduction}

Rapid climate change, stressed ecosystems and sharp declines in biodiversity are all indicators of the accelerating pace and global scale of human impacts on the Earth system (Johnson et al. 2017). Such environmental upheavals, effectively captured in the 'Anthropocene' concept (Steffen et al. 2007), challenge classical approaches to conserving biodiversity such as setting aside protected areas: nowhere on Earth is now completely isolated from the impacts of human activities (Scheffers et al. 2016). Compounding the myriad of threats to biodiversity are the dynamic human adaptive responses to environmental change, such as major engineering and infrastructure developments, shifts in demographic and agricultural patterns, strategies to reduce the impacts of extreme events, and attempts to improve the security of water, food and energy (Maxwell et al. 2015).

Recognition of the rate, scale and magnitude of the global environmental crisis has triggered debate about whether existing conservation approaches and intellectual disciplines are adequate (Harmsen and Foster 2014; Hobbs 2013; Martin et al. 2012; Robbins and Moore 2013; Head 2016) (Box 1). One important source of intellectual tension concerns the weight placed on historical frames of reference to define management strategies and objectives (Rohwer \& Marris 2016). In a world where the physical underpinnings of ecosystems are changing rapidly, a focus on the past as an ideal standard can be unhelpful in places where it is no longer possible to sustain ecosystems within the range of known historical variability (Kareiva \& Fuller 2016). Conservation biology, restoration ecology and invasion biology have been criticized as 'Edenic sciences', given their common objective of returning ecosystems to a past, often idealized, state (Stott 1998; Robbins \& Moore 2013). Ecosystems in the Anthropocene may have no historical analog and harbour a range of non-native species, some of which may be threatened within their historic ranges.

This article is protected by copyright. All rights reserved. 
The emergence of such novel ecosystems (Hobbs et al. 2006) confronts the 'natural system' archetype as the basis of conservation biology (Hagerman \& Satterfield 2014). Kareiva \& Fuller (2016), for example, argue that current conservation approaches are inadequately equipped for the challenges of the Anthropocene due to entrenched risk aversion - codified in the 'precautionary principle'. There is certainly concern about assisting the movement of species in the face of climate change (Ricciardi \& Simberloff 2009) and that a focus on novel ecosystems provides an excuse for accepting as inevitable the loss of natural systems (Murcia et al. 2014). Many, but not all, of those resisting ecological interventions acknowledge that conservation science needs to be conducted in the face of rapid climate change. Arguably, urban ecologists have most fully accepted the novel ecosystem concept (Hobbs et al. 2006) and the blurring of boundaries between natural and human-dominated ecosystems, recognizing biodiversity values in settings that have been typically considered severely degraded or otherwise profoundly altered by human activities. Given the enormity of change that all ecosystems are facing, we suggest that a new approach is required for designing and managing biodiverse ecosystems and providing human wellbeing in the Anthropocene. Such an approach must also minimise the collateral damage of human adaptation and development in an anticipatory, proactive and collaborative way.

\section{Concept definition}

We propose the concept of renewal ecology as an organizing principle for conservation management in the Anthropocene. This concept formally recognizes that rapid environmental change is unavoidable, necessitating critical planning and action, but also that human modifications of landscapes for provision of food, fibre and ecosystem services do not necessarily have to come at the expense of biodiversity. We contend that renewal ecology provides a philosophical license for ecologists to sustain biodiversity in the Anthropocene through innovation, and represents a channel for optimistic conservation action in a time of inevitable environmental change. We define renewal ecology as the science essential for creating and managing ecosystems to maximize both biodiversity and human wellbeing in the face of rapid environmental change. We intentionally advocate a broad definition of renewal ecology because, like the concept of 'biodiversity', it provides flexibility in interpretation (Higgs 2003), and is more likely to contribute to 'creating a shared vision and vocabulary' that will bring scientists, practitioners and politicians 'closer to creating landscapes that 
will sustain human well-being and forecast a more promising future for all species on our shared planet' (Chazdon \& Laestadius 2016).

\section{Concept examples}

Below we illustrate how the renewal ecology concept provides a unifying framework for innovative conservation practice across environments ranging from aquatic, wildland, agricultural and urban ecosystems. We briefly describe some examples of how human modifications to land-, freshwaterand seascapes aimed at reducing the negative impacts of climate change, can, if approached in a forward-looking and innovative way, provide substantial co-benefits for biodiversity. The salient feature of these examples is that existing techniques (drawn from a range of disciplines such as restoration ecology, environmental engineering, agricultural science, forestry, fisheries, conservation biology and wildlife management) can be combined and applied across a range of environments, land tenures and spatial scales to improve biodiversity outcomes. Such an approach actively seeks opportunities to modify engineering, urban and landscape design as well as approaches to agricultural and land and water management to create more coherence between human societies and economies, land- and seascapes and biodiversity. Even small interventions can have far reaching impacts on society and biodiversity which in turn can energise innovation and larger scale transformative adaptation to global environmental changes. The drivers for these changes may be corporate innovation seeking environmental sustainability and social legitimacy (Kareiva \& Fuller 2016), but can also occur across sectors in society as a result of government regulation and policy.

\section{Living shorelines to protect coasts}

Sea level rise and the associated increased risks of storm surges and coastal flooding are leading to substantial increases in "hard-engineering" solutions (i.e. seawalls, revetments, breakwaters, groynes, and barrages) to protect coastal infrastructure from inundation and erosion (Bulleri \& Chapman 2010). These approaches can have substantial negative impacts on coastal ecosystems, including loss of habitat, disruption of land-sea and long-shore connectivity of organisms and resources, and facilitation of movement by marine pest species (Bulleri \& Chapman 2010).

This article is protected by copyright. All rights reserved. 
A renewal ecology approach to coastal adaptation might instead include the construction of ecosystems such as coral and shellfish reefs, mangroves and/or saltmarsh to dissipate wave action and stabilise shorelines (Arkema et al. 2013). The use of 'living shorelines' for coastal protection has the added benefit that these ecosystems can enhance other services such as fisheries productivity and sequestration of carbon (Barbier et al. 2011). Such land-sea connectivity and access to biodiverse beaches also provide meaningful experiences to humans, especially for urban shorelines. Where defence of coasts using hard-engineering structures remains necessary, their deleterious impacts can be substantially reduced by incorporating important micro-habitats such as tidal pools and crevices, and constructing them of materials that provide a substrate to support a broad spectrum of marine and estuarine organisms. In some instances, the positioning of hard-engineering structures in sedimentary environments may provide important 'stepping stones' for hard-substrate dependent species to overcome dispersal barriers and migrate poleward in response to climate change.

Innovative plantings to reduce fire risk

In environments dominated by temperate forests and shrublands prone to crown-fires, increases in extreme heat and changed rainfall patterns are increasing the frequency and intensity of wildfires (McKenzie et al. 2016). Exposure of high value property, such as urban housing, to regular wildfires is acute in parts of the world such as southern California, Canada, southern Australia and southern Europe (Moritz et al. 2014). The challenge of coping with the increasing risk to people and property is compounded by ongoing urban expansion into areas of highly flammable vegetation (Bowman et al. 2017).

Strategies to reduce fire risk can provide opportunities and choices for biodiversity within a renewal ecology framework. For example, treatment of fuel may be more effectively achieved through permanent modification of natural vegetation close to urban settlements, rather than using prescribed fire, which is both costly (Penman et al. 2013) and hazardous to the health of residents through exposure to smoke (Broome et al. 2016). Creation of linear parklands substituting low- for high-flammability vegetation (e.g. rainforest or Callitris spp. instead of Eucalyptus spp. in Australia) that separate wildland and urban areas may provide alternative habitats for species and amenity values for urban residents while at the same time reducing direct exposure of properties to fire risk. In particular, the opportunities to create a fine-scale mosaic of varied habitats may arise through 
deliberate plantings of vegetation less prone to propagation of crown fires and embers. This may enhance fine-scale diversity relative to simplification of native vegetation via mechanical clearing or other forms of repetitive fuel treatment, such as prescribed burning.

Greening to cool cities and connect people to nature

Globally, the number of people living in urban environments already exceeds those outside cities. By $2050,66 \%$ of the world's projected population of about 9.7 billion is expected to be urban (United Nations 2015). With rising temperatures, exacerbated by the urban heat island effect, the human population is expected to spend more time indoors in air-conditioned environments, increasing energy consumption and reducing connection with nature (Shanahan et al. 2014).

Application of renewal ecology concepts to urban environments starts with biodiversity-sensitive design, moving beyond existing approaches that focus on preserving remnants, to incorporating biodiversity into the urban fabric (Garrard et al. in review). Greening urban environments can generate physical and mental health benefits; reduce energy consumption by buffering microclimates and reduce the urban heat island effect; store carbon; alleviate the impacts of flooding by reducing peaks in storm water runoff; provide shelter from extreme weather; and contribute to biodiversity conservation, particularly threatened plant and animal species. The design elements that would characterize a renewal ecology approach to cities could include vegetated roofs and walls and purpose-designed and built structures that enable safe movements of animals across the landscape, reducing road-kill and the effects of habitat fragmentation (Laurance et al. 2014). Creating opportunities for urban residents to engage with nature where they live, work, play and travel can potentially be achieved through sensitive urban design that integrates both native and non-native plants and animals into courtyards, school yards, suburban gardens and transport corridors.

Water to sustain people and species

Freshwater and coastal species are already among the most threatened as a consequence of their habitats being a focus of human settlements and livelihoods, and because global consumption of water is increasing with growing populations and greater wealth. Freshwater ecosystems are particularly vulnerable to human impacts from activities in water catchments, fragmentation of rivers

This article is protected by copyright. All rights reserved. 
by infrastructure, and from water consumption that alters the quality, quantity and timing of water flows (Pittock et al. 2015). All these effects are exacerbated by climate change. Many of the most serious impacts of climate change on people and biodiversity are felt via impacts on water, including floods, droughts, storms and changes in rainfall distribution (Bates et al. 2008). In addition to the direct impacts on biodiversity, many human responses to climate change will detrimentally affect aquatic ecosystems (Pittock 2015). These include mitigation measures that consume more water, such as many types of biofuel production, and adaptation measures, including increased storage of water in reservoirs.

ㅁ.

A renewal ecology approach to water management would aim to meet human needs while sustaining aquatic biodiversity. There are a number of existing examples of interventions consistent with this philosophy that are currently implemented in an ad hoc manner. These include: environmental water releases that mimic pre-development river flows so as to conserve selected biodiversity; reserving aquatic refugia that also offer recreational opportunities; adding fish ladders to reservoirs to assist migration; systematically restoring riparian vegetation to cool rivers, reduce erosion and provide habitat and opportunities for recreation; and the removal of redundant dams. Integrated implementation of these established practices can enhance the catchment-scale functioning of aquatic systems and link urban, agricultural and natural areas.

Biodiversity opportunities from changing agricultural practices

Farmers are modifying agricultural landscapes to remain economically viable in a changing climate (Nelson et al. 2014). Relatively simple modifications include adopting land use practices that reduce water loss (e.g. conservation tillage); adopting geospatial precision farming technologies; and switching to more heat-tolerant livestock breeds. Where changing conditions make existing agricultural systems untenable, major modifications are leading to some agricultural systems being replaced, displaced or abandoned entirely (Rickards \& Howden 2012).

Adapting agricultural landscapes to climate change could potentially exacerbate their already substantial impacts on biodiversity (Maxwell et al. 2016). Adopting a renewal ecology approach to adaptation, however, could mitigate and potentially reverse some of these impacts. Heat stress in livestock can be mediated by establishing tree plantations alongside grazing areas, and biodiversity 
can benefit from such planting if they are made species-rich and permanent (Karki \& Goodman 2010). Shifts to grazing in regions where declining rainfall is making cropping unviable may offer opportunities for creation of critical habitat for threatened species, enhanced pollination and shelter services, and potentially pest, disease and weed management services. Finally, abandoned farmland offers opportunities to reconnect remnant vegetation or to recreate highly threatened ecosystem types, such as native grassland or grassy woodland (Ceausu et al. 2015; Middendorp et al. 2016).

Cohabitation of species and renewable energy sources

Almost all forms of power generation have the potential to harm biodiversity. For instance, poorly placed wind generators can harm fauna and unconventional (i.e. coal seam and shale) gas as a lower carbon 'transition fuel' could reduce biodiversity by increasing access to little developed regions, increasing habitat fragmentation and polluting freshwater ecosystems (Cook et al. 2013). Carbon capture and geological storage (Carter 2015), nuclear power, first generation biofuel crops, (CBD 2010; Dalla Marta et al. 2015) and solar thermal power stations (Pittock et al. 2013) all affect freshwater sources as does planting forests to mitigate emissions by increasing water consumption rates (Pittock et al. 2013). Hydropower dams also have severe impacts on freshwater ecosystems.

A renewal ecology approach adapts the design of the new systems to minimize losses and maximize opportunities. For example, the large areas of land and sea occupied by solar and wind generators offer opportunities for cohabitation with biodiversity, especially where the land has been degraded. In the sea, offshore wind and wave farms serve as de facto marine protected areas because trawl fishing, a major source of marine habitat degradation, is excluded (Ashley et al. 2014). The foundations of offshore energy harnessing infrastructure may be co-designed to serve as artificial reefs, or anchor points for aquaculture that might otherwise pollute habitats closer inshore (Buck et al. 2004).

\section{Creating positive legacies from abandoned mines}

Classically, the objective of post-mining rehabilitation has been to replace destroyed ecosystems, although this is rarely achieved (Bell 2001). By leveraging off the substantial financial resources and equipment available for mine site restoration programs, a renewal ecology approach would focus on the deliberate creation of novel ecosystems and landscapes designed to provide habitat and 
sanctuaries for both native and non-native threatened species (Harris et al. 2013). Examples of postmining land that have become biodiversity hotspots demonstrate that this approach is feasible. For instance, wetlands created from rehabilitated sand-mined areas have provided bird habitat in southwestern Western Australia (Brooks \& Nichols 1996) and the largest known breeding site for ghost bats in the Northern Territory, Australia (Woinarski et al. 2014).

\section{Conclusions}

Growing human populations and associated environmental impacts on the Earth system are driving ecological degradation and the ongoing extinction crisis. This presents profound challenges to the principles and practice of applied ecology, with growing acceptance that the future of biodiversity and the provision of ecosystem services will depend on more radical interventions than have been previously countenanced, including the intentional creation of novel ecosystems. Engineering and technological interventions have the potential either to exacerbate or mitigate ecosystem damage. We argue that ecologists must promote opportunities to integrate ecosystem processes and biodiversity into landscape-scale interventions, a concept we call 'renewal ecology'. We provide examples of this approach in the freshwater, marine and terrestrial environments.

In a period of rapid change all strategies carry risk of failure. We therefore see the potential of renewal ecology as being additional to existing conservation approaches rather than as a call to replace them. In this context, the concept espoused by Aplet and Gallo (2012) of a "portfolio approach" to nature conservation is pertinent. Such an approach across landscapes is based on different principles and practices ranging from the classic nature reserve to more innovative, experimental and historical approaches inherent in renewal ecology. This hedges against the failure of any particular approach to biodiversity protection and human wellbeing. Such plurality of approaches reduces rather than exacerbates philosophical tensions amongst conservation practitioners. Importantly renewal ecology can motivate other sectors in the economy to incorporate biodiversity into their current and future responses to climate change, thereby increasing the economic base and area for conservation (Rosenzweig 2003). In sum, renewal ecology is a project reconciling humans and nature, of co-creating a vibrant, diverse world for humans and other species. Though there will 
undoubtedly be missteps and mistakes along the way, this approach promises the possibility of a world that, while changed, is greener, wilder and happier than today.

\section{Acknowledgements}

This paper is a product of a National Climate Change Adaptation Facility (NCCARF) workshop organized by Lesley Hughes and Stephen T. Garnett.

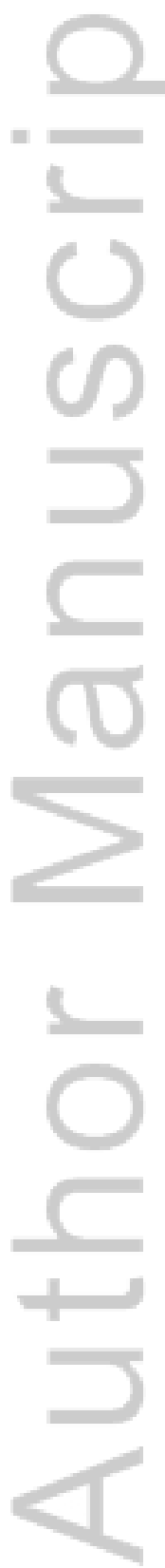

This article is protected by copyright. All rights reserved. 


\section{References}

Arkema KK, Guannel G, Verutes G, Wood SA, Guerry A, Ruckelshaus M, Kareiva P, Lacayo M, Silver JM (2013) Coastal habitats shield people and property from sea-level rise and storms. Nature Climate Change 3:913-918

Ashley MC, Mangi SC, Rodwell LD (2014) The potential of offshore windfarms to act as marine protected areas-a systematic review of current evidence. Marine Policy 45:301-309

Barbier EB, Hacker SD, Kennedy C, Koch EW, Stier AC, Silliman BR (2011) The value of estuarine and coastal ecosystem services. Ecological Monographs 81:169-193

Bates BC, Kundzewicz ZW, Wu S, Palutikof JP (2008) Climate Change and Water. Technical Paper of the Intergovernmental Panel on Climate Change (IPCC). IPCC, Geneva

Bell LC (2001) Establishment of native ecosystems after mining - Australian experience across diverse biogeographic zones. Ecological Engineering 17:179-186

Bowman DMJS, Williamson GJ, Abatzoglou JT, Kolden CA, Cochrane MA, Smith AMS (2017) Human exposure and sensitivity to globally extreme wildfire events. Nature Ecology and Evolution 1: article 58

Brooks DR, Nicholls FM (1996) Environmental management and wetlands development at Capel in Southwest Western Australia. Pages 557-570 In: Mulligan DR (ed) Environmental Management in the Australian Minerals and Energy Industries: Principles and Practice. University of New South Wales Press, Sydney

Broome RA, Johnston FH, Horsley J, Morgan GG (2016) A rapid assessment of the impact of hazard reduction burning around Sydney, May 2016. Medical Journal of Australia 205:407-408

Buck BH, Krause G, Rosenthal H (2004) Extensive open ocean aquaculture development within wind farms in Germany: the prospect of offshore co-management and legal constraints. Ocean \& Coastal Management 47:95-122 
Bulleri F, Chapman MG (2010) The introduction of coastal infrastructure as a driver of change in marine environments. Journal of Applied Ecology 47:26-35

CBD (2010) X/37. Biofuels and biodiversity. UNEP/CBD/COP/DEC/X/37. Convention on Biological Diversity, Montreal

Ceausu S, Hofmann M, Navarro LM, Carver S, Verburg PH, Pereira HM (2015) Mapping opportunities and challenges for rewilding in Europe. Conservation Biology 29:1017-1027

Chazdon RL, Laestadius L (2016) Forest and landscape restoration: toward a shared vision and vocabulary. American Journal of Botany 103:1869-1871

Cook P, Beck V, Brereton D, Clark R, Fisher B, Kentish S, et al. (2013) Engineering energy: unconventional gas production. Australian Council of Learned Academies, Melbourne Dalla Marta A, Orlando F, Mancici M, Orlandini S (2015) Water and biofuels. Pages 108-122 In: Pittock J, Hussey K, Dovers S (eds) Climate, energy and water. Cambridge University Press, Cambridge Hagerman SM, Satterfield T (2014) Agreed but not preferred: expert views on taboo options for biodiversity conservation, given climate change. Ecological Applications 24:548-559

Harris S, Arnall S, Byrne M, Coates D, Garnett ST, Hayward M, Martin T, Mitchell N (2013) Whose backyard? Choosing sites for assisted colonisation. Ecosystem Management and Restoration 14:106111

Head L (2016) Hope and Grief in the Anthropocene: re-conceptualising Human-Nature Relations. Routledge, New York

Higgs E (2003) Nature by Design: People, Natural Process, and Ecological Restoration. MIT Press, Cambridge, Massachusetts

Hobbs RJ, Arico S, Aronson J, Baron JS, Bridgewater P, Cramer VA, Epstein PR, Ewel JJ, et al. (2006) Novel ecosystems: theoretical and management aspects of the new ecological world order. Global Ecology and Biogeography 15:1-7

This article is protected by copyright. All rights reserved. 
Hobbs RJ, Hallett LM, Ehrlich PR, Mooney HA (2011) Intervention ecology: applying ecological science in the twenty-first century. BioScience 61:442-450

Kareiva P, Fuller E (2016) Beyond resilience: how to better prepare for the profound disruption of the Anthropocene. Global Policy 7:107-118

Laurance WF, Clements GR, Slan S, O'Connell CS, Mueller ND, Goosem M, Venter O, Edwards DP, Phalan B, Balmford A, Van Der Ree R, Arrea IB (2014) A global strategy for road building. Nature $513: 229-232$

부요

Martin LJ, Quinn JE, Ellis EC, Shaw MR, Dorning MA, Hallett LM, Heller NE, Hobbs RJ, Kraft CE, Law E, Michel NL (2014) Biodiversity conservation opportunities across the world's anthromes. Diversity and Distributions 20:745-755

Maxwell S, Fuller R, Brooks T, Watson J (2016) Biodiversity: the ravages of guns, nets and bulldozers. Nature 536:143

Maxwell S, Venter O, Jones KR, Watson, JEM (2015) Integrating human responses to climate change into conservation vulnerability assessments and adaptation planning. Annals of the New York Academy of Sciences 1355:98-116

McKenzie D, Littell J (2016) Climate change and the eco-hydrology of fire: will area burned increase in a warming western U.S.? Ecological Applications, published online, doi:10.1002/eap.1420

Middendorp, RS, Perez AJ, Molina A, Lambin, EF (2016) The potential to restore native woody plant richness and composition in a reforesting landscape: a modeling approach in the Ecuadorian Andes. Landscape Ecology 31:1581-1599

Moritz MA, Batllori E, Bradstock RA, Gill AM, Handmer J, Hessburg PF, Leonard J, McCaffrey S, Odion DC, Schoennagel T, Syphard AS (2014) Learning to Coexist with Wildfire. Nature 515:58-66

Murcia C, Aronson J, Kattan GH, Moreno-Mateos D, Dixon K, Simberloff D (2014) A critique of the 'novel ecosystem'concept. Trends in Ecology \& Evolution 29:48-53

This article is protected by copyright. All rights reserved. 
Myers N (1993) Biodiversity and the precautionary principle. Ambio 22:74-79

Nelson GC, Valin H, Sands RD, Havlík P, Ahammad H, Deryng D, et al. (2014) Climate change effects on agriculture: economic responses to biophysical shocks. Proceedings of the National Academy of Sciences 111:3274-3279

Penman TD, Bradstock RA, Price OF (2013) Reducing wildfire risk to urban developments: simulation of cost-effective fuel treatment solutions in south eastern Australia. Environmental Modelling and Software 52:166-175

Perrings C, Jackson L, Bawa K, Brussaard L, Brush S, Gavin T, Papa R, Pascual U, De Ruiter P (2006) Biodiversity in agricultural landscapes: saving natural capital without losing interest. Conservation Biology 20:263-264

Pittock J (2015) Biodiversity and the climate, energy and water nexus. Pages 283-302 In: Pittock J, Hussey K, Dovers S (eds) Climate, energy and water. Cambridge University Press, Cambridge

Pittock J, Finlayson M, Arthington AH, Roux D, Matthews JH, Biggs H, et al. (2015) Managing freshwater, river, wetland and estuarine protected areas. Pages 569-608 In: Worboys GL, Lockwood M, Kothari A, Feary S and Pulsford I (eds) Protected area governance and management. ANU Press, Canberra

Pittock J, Hussey, K, McGlennon S (2013) Australian Climate, Energy and Water Policies: conflicts and synergies. Australian Geographer 44:3-22.

Ricciardi A, Simberloff D (2009) Assisted colonization is not a viable conservation strategy. Trends in Ecology \& Evolution 24:248-253

Rickards L, Howden SM (2012) Transformational adaptation: agriculture and climate change. Crop Pasture Science 63:240-250

Rohwer Y, Marris E (2016) Renaming restoration: conceptualizing and justifying the activity as a restoration of lost moral value rather than a return to a previous state. Restoration Ecology 24:674679 
Shanahan DF, Lin BB, Gaston KJ, Bush R, Fuller RA (2014) Socio-economic inequalities in access to nature on public and private lands: a case study from Brisbane, Australia. Landscape and Urban Planning 130:14-23

Scheffers BR, De Meester L, Bridge TCL, Hoffmann AA, Pandolfi JM, Corlett RT, Butchart AHM, PearceKelly P, Kovacs KM, Dudgeon D, et al. (2016) The broad footprint of climate change from genes to biomes to people. Science 354: doi: 10.1126/science.aaf7671

Steffen W, Crutzen PJ, McNeill JR (2007) The Anthropocene: are humans now overwhelming the great forces of nature. Ambio 36:614-621

Stott P (1998) Editorial: biogeography and ecology in crisis: the urgent need for a new metalanguage. Journal of Biogeography 25:1-2

Syphard A, Butsic V, Bar-Massada A, Keeley J, Tracey J, Fisher R (2016) Setting priorities for private land conservation in fire-prone landscapes: are fire risk reduction and biodiversity conservation competing or compatible objectives? Ecology \& Society 21: article 2

United Nations (2015) World Population Prospects: the 2015 revision: key findings and advance tables. Department of Economic and Social Affairs, Population Division. United Nations, New York

Woinarski JCZ, Burbidge, AA, Harrison, PL (2014) The Action Plan for Australian Mammals 2012. CSIRO Publishing, Canberra

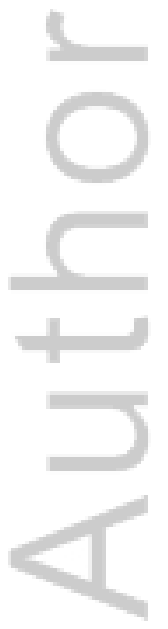

This article is protected by copyright. All rights reserved. 


\section{Box 1: Definition of Renewal Ecology and its relationship to related disciplines}

There is increasing recognition that classical approaches to conservation and natural resources management are unable to meet the challenges of the Anthropocene. Martin et al. (2014) provide a valuable summary (their Table 1) of how existing scientific fields, and proposed new ones, and associated concepts can contribute to conservation goals and human livelihoods in the face of global environmental change. Our concept of renewal ecology, defined as "a solutions-focused discipline aimed at creating and managing ecosystems designed to maximize both biodiversity and human wellbeing in the face of rapid environmental change" builds on these approaches, and below we briefly outline (in alphabetical order) how renewal ecology differs or enhances some key related fields and concepts.

Agroecology: Renewal ecology incorporates the argument of Perrings et al. (2006) that understanding agriculture as an ecological system, where biodiversity plays a critical beneficial role for food production and provision of ecosystems, is essential given increasing conversion of wildland to agriculture to feed increasing human populations.

Compassionate conservation: an approach to management of trophic interactions to reduce the need for lethal control to stabilise wildlife and pest species (Ramp \& Bekoff 2015). Such ethical consideration of the treatment of the non-human world is shared in renewal ecology.

Conservation biology: aimed at reducing the risk of extinction of non-human species and degradation of their habitats and the services they provide, taking past abundance, composition and/or structure as an aspirational standard. We propose renewal ecology as more forward-looking than traditional conservation biology, focusing on adaptation opportunities that provide benefits for biodiversity while people directly or indirectly adapt to global change.

Conservation science: proposed by Kareiva and Marvier (2012) to make conservation biology more responsive and relevant to current threats through the 'application of both natural and social sciences to the dynamics of coupled human-natural systems'. They argue that human well-being and social justice must be central to all conservation efforts with a focus on provision of ecosystems services, an 
ethos central to renewal ecology.

\section{Human ecology/Coupled human-natural systems/Social-ecological systems (herein termed 'human}

ecology'): the interdisciplinary and trans-disciplinary study of the relationship between humans and their natural and built environments. In clearly defined and data-rich systems, methodologies developed in human ecology can be employed to evaluate likely biodiversity and human benefits associated with alternative renewal ecology interventions. Such holistic understanding of human nature coupling is fundamental to the practice of renewal ecology.

Intervention ecology: Hobbs et al. (2011) outlined the case for steering restoration ecology and land management towards a more 'thoughtful experimental approach embedded in adaptive management' and have suggested the term 'intervention ecology' to capture approach. Renewal ecology builds on this argument by focusing on the need to design ecosystems consciously and manage them actively, using targeted interventions in the face of unprecedented environmental change.

Novel ecosystems: the concept that new assemblages of species (i.e. those that have no historical precedent) will result from differential responses to global change (Hobbs et al. 2006). These assemblages may be biodiverse, functional, resilient, and self-sustaining. Renewal ecology is aimed at managing the trajectory of such novel assemblages to maximize biodiversity and services.

Precautionary principle and biodiversity: The principle of 'do no harm' and placing the 'burden of proof' on proponents of environmental change lie at the heart of the precautionary principle. But an overly cautious approach to undertaking active interventions to save species can, in itself, contribute to extinction risk (Myers 1993). Renewal ecology argues for bet-hedging, rather than risk aversion inherent in 'intervention ecology' (see above).

Reconciliation ecology: Rosenzweig (2003) presciently recognized that effort should be made to modify diverse anthropogenic landscapes to create habitat for species, thereby increasing biodiversity. Renewal ecology embraces this idea but, because of the pervasive effects of global environmental change, applies it to all natural systems.

This article is protected by copyright. All rights reserved. 
Restoration ecology: has generally been aimed at assisting the recovery of ecosystems that have been degraded or destroyed to return to a previous, indigenous, state. Renewal ecology recognizes that in many cases, the rapidity of environmental change means that such an objective is unlikely to be achieved and instead promotes the creation and/or enhancement of landscapes that support biodiversity and provide ecosystem services for human communities in the context of change.

Urban ecology: the study of the relationships and interactions between all organisms - human and non-human - within this most anthropogenic of landscapes. This discipline can be regarded as a fundamental component of renewal ecology.

This article is protected by copyright. All rights reserved. 
Zander Kerstin (Orcid ID: 0000-0002-2237-1801)

\section{Renewal Ecology: Conservation for the Anthropocene}

Running head: Renewal Ecology

Bowman DMJS', Garnett $\mathrm{ST}^{2}$, Barlow EWR ${ }^{3}$, Bekessy $\mathrm{SA}^{4}$, Bellairs $\mathrm{SM}^{2}$, Bishop MJ $\mathrm{J}^{5}$, Bradstock RA ${ }^{6}$, Jones $\mathrm{DN}^{7}$, Maxwell SL ${ }^{8}$, Pittock $\mathrm{J}^{9}$, Toral-Granda $\mathrm{MV}^{2}$, Watson JEM ${ }^{8,10}$, Wilson $\mathrm{T}^{11}$, Zander $\mathrm{KK}^{11}$, Hughes $\mathrm{L}^{5^{*}}$<smiles>[CH]CC</smiles>

1. School of Biological Sciences, University of Tasmania, Private Bag 55, Hobart, Tasmania 7001, Australia

2. Research Institute for the Environment and Livelihoods, Charles Darwin University, Casuarina, Northern Territory 0909, Australia

3. Faculty of Veterinary and Agricultural Sciences, University of Melbourne, Parkville, Victoria 3011, Australia

4. Interdisciplinary Conservation Science Research Group, School of Global, Urban and Social Studies, RMIT University, GPO Box 2476, Melbourne 3001, Australia

5. Dept. of Biological Sciences, Macquarie University, North Ryde, New South Wales 2109, Australia

6. Centre for Environmental Risk Management of Bushfires, University of Wollongong, New South Wales 2522, Australia

7. Environmental Futures Research Institute, Griffith University, Nathan QLD 4111, Australia

8. School of Earth and Environmental Sciences, The University of Queensland, St Lucia QLD 4072, Australia

9. Fenner School of Environment and Society, The Australian National University, 48 Linnaeus Way, Acton ACT 2600, Australia

10. Wildlife Conservation Society, Global Conservation Program, Bronx NY 10460 USA

11. Northern Institute, Charles Darwin University, Casuarina, NT 0909, Australia

${ }^{*}$ Corresponding author

This article is protected by copyright. All rights reserved. 


\section{Author Contributions}

This paper is a product of a National Climate Change Adaptation Facility (NCCARF) workshop organized by LH and STG. All authors contributed to the writing of the paper: DMJSB, STG, LH and KKZ lead the writing with case studies drafted by MJB (coasts), RAB (fire-breaks), SAB and DNJ (urban ecology), JP (freshwater and energy), SLM and EWRB (agriculture) and SMB and DMJSB (mines).

\section{Abstract}

The global-scale and rapidity of environmental change is challenging ecologists to re-imagine their theoretical principles and management practices. Increasingly, historical ecological conditions are inadequate targets for restoration ecology, geographically circumscribed nature reserves are incapable of protecting all biodiversity, and the precautionary principle applied to management interventions no longer ensures avoidance of ecological harm. In addition, human responses to global environmental changes, such as migration, building of protective infrastructures, and land use change, are having their own negative environmental impacts. We use examples from wildlands, urban and degraded environments, as well as marine and freshwater ecosystems, to show that human adaptation responses to rapid ecological change can be explicitly designed to benefit biodiversity. This approach, which we call 'renewal ecology', is based on acceptance that environmental change will have transformative effects on coupled human and natural systems and recognizes the need to harmonise biodiversity with human infrastructure, for the benefit of both.

Keywords: social-ecological systems, climate, biodiversity, environmental change, opportunity, innovation

\section{Implications}

i. By accepting environmental change as inevitable and irrevocable, renewal ecology provides those practicing conservation management greater social license to innovate.

ii. Irretrievably degraded land and seascapes can provide opportunities to renew biological function and diversity, in places where attempts to recreate the former natural state would fail.

iii. Urban and agricultural landscapes largely written off as sites for effective conservation can be re-imagined as species habitat with enhanced ecological functionality, while delivering cobenefits for human wellbeing.

This article is protected by copyright. All rights reserved. 


\section{Introduction}

Rapid climate change, stressed ecosystems and sharp declines in biodiversity are all indicators of the accelerating pace and global scale of human impacts on the Earth system (Johnson et al. 2017). Such environmental upheavals, effectively captured in the 'Anthropocene' concept (Steffen et al. 2007), challenge classical approaches to conserving biodiversity such as setting aside protected areas: nowhere on Earth is now completely isolated from the impacts of human activities (Scheffers et al. 2016). Compounding the myriad of threats to biodiversity are the dynamic human adaptive responses to environmental change, such as major engineering and infrastructure developments, shifts in demographic and agricultural patterns, strategies to reduce the impacts of extreme events, and attempts to improve the security of water, food and energy (Maxwell et al. 2015).

Recognition of the rate, scale and magnitude of the global environmental crisis has triggered debate about whether existing conservation approaches and intellectual disciplines are adequate (Harmsen and Foster 2014; Hobbs 2013; Martin et al. 2012; Robbins and Moore 2013; Head 2016) (Box 1). One important source of intellectual tension concerns the weight placed on historical frames of reference to define management strategies and objectives (Rohwer \& Marris 2016). In a world where the physical underpinnings of ecosystems are changing rapidly, a focus on the past as an ideal standard can be unhelpful in places where it is no longer possible to sustain ecosystems within the range of known historical variability (Kareiva \& Fuller 2016). Conservation biology, restoration ecology and invasion biology have been criticized as 'Edenic sciences', given their common objective of returning ecosystems to a past, often idealized, state (Stott 1998; Robbins \& Moore 2013). Ecosystems in the Anthropocene may have no historical analog and harbour a range of non-native species, some of which may be threatened within their historic ranges.

The emergence of such novel ecosystems (Hobbs et al. 2006) confronts the 'natural system' archetype as the basis of conservation biology (Hagerman \& Satterfield 2014). Kareiva \& Fuller (2016), for example, argue that current conservation approaches are inadequately equipped for the challenges of the Anthropocene due to entrenched risk aversion - codified in the 'precautionary principle'. There is certainly concern about assisting the movement of species in the face of climate change (Ricciardi \& Simberloff 2009) and that a focus on novel ecosystems provides an excuse for accepting as inevitable the loss of natural systems (Murcia et al. 2014). Many, but not all, of those resisting ecological interventions acknowledge that conservation science needs to be conducted in the face of rapid climate change. Arguably, urban ecologists have most fully accepted the novel ecosystem concept (Hobbs et al. 2006) and the blurring of boundaries between natural and human-dominated ecosystems, recognizing biodiversity values in settings that have been typically considered severely

This article is protected by copyright. All rights reserved. 
degraded or otherwise profoundly altered by human activities. Given the enormity of change that all ecosystems are facing, we suggest that a new approach is required for designing and managing biodiverse ecosystems and providing human wellbeing in the Anthropocene. Such an approach must also minimise the collateral damage of human adaptation and development in an anticipatory, proactive and collaborative way.

\section{Concept definition}

We propose the concept of renewal ecology as an organizing principle for conservation management in the Anthropocene. This concept formally recognizes that rapid environmental change is unavoidable, necessitating critical planning and action, but also that human modifications of landscapes for provision of food, fibre and ecosystem services do not necessarily have to come at the expense of biodiversity. We contend that renewal ecology provides a philosophical license for ecologists to sustain biodiversity in the Anthropocene through innovation, and represents a channel for optimistic conservation action in a time of inevitable environmental change. We define renewal ecology as the science essential for creating and managing ecosystems to maximize both biodiversity and human wellbeing in the face of rapid environmental change. We intentionally advocate a broad definition of renewal ecology because, like the concept of 'biodiversity', it provides flexibility in interpretation (Higgs 2003), and is more likely to contribute to 'creating a shared vision and vocabulary' that will bring scientists, practitioners and politicians 'closer to creating landscapes that will sustain human well-being and forecast a more promising future for all species on our shared planet' (Chazdon \& Laestadius 2016).

\section{Concept examples}

Below we illustrate how the renewal ecology concept provides a unifying framework for innovative conservation practice across environments ranging from aquatic, wildland, agricultural and urban ecosystems. We briefly describe some examples of how human modifications to land-, freshwaterand seascapes aimed at reducing the negative impacts of climate change, can, if approached in a forward-looking and innovative way, provide substantial co-benefits for biodiversity. The salient feature of these examples is that existing techniques (drawn from a range of disciplines such as restoration ecology, environmental engineering, agricultural science, forestry, fisheries, conservation biology and wildlife management) can be combined and applied across a range of environments, land tenures and spatial scales to improve biodiversity outcomes. Such an approach actively seeks opportunities to modify engineering, urban and landscape design as well as approaches to agricultural and land and water management to create more coherence between human societies and economies, 
land- and seascapes and biodiversity. Even small interventions can have far reaching impacts on society and biodiversity which in turn can energise innovation and larger scale transformative adaptation to global environmental changes. The drivers for these changes may be corporate innovation seeking environmental sustainability and social legitimacy (Kareiva \& Fuller 2016), but can also occur across sectors in society as a result of government regulation and policy.

\section{Living shorelines to protect coasts}

Sea level rise and the associated increased risks of storm surges and coastal flooding are leading to substantial increases in "hard-engineering" solutions (i.e. seawalls, revetments, breakwaters, groynes, and barrages) to protect coastal infrastructure from inundation and erosion (Bulleri \& Chapman 2010). These approaches can have substantial negative impacts on coastal ecosystems, including loss of habitat, disruption of land-sea and long-shore connectivity of organisms and resources, and facilitation of movement by marine pest species (Bulleri \& Chapman 2010).

A renewal ecology approach to coastal adaptation might instead include the construction of ecosystems such as coral and shellfish reefs, mangroves and/or saltmarsh to dissipate wave action and stabilise shorelines (Arkema et al. 2013). The use of 'living shorelines' for coastal protection has the added benefit that these ecosystems can enhance other services such as fisheries productivity and sequestration of carbon (Barbier et al. 2011). Such land-sea connectivity and access to biodiverse beaches also provide meaningful experiences to humans, especially for urban shorelines. Where defence of coasts using hard-engineering structures remains necessary, their deleterious impacts can be substantially reduced by incorporating important micro-habitats such as tidal pools and crevices, and constructing them of materials that provide a substrate to support a broad spectrum of marine and estuarine organisms. In some instances, the positioning of hard-engineering structures in sedimentary environments may provide important 'stepping stones' for hard-substrate dependent species to overcome dispersal barriers and migrate poleward in response to climate change.

Innovative plantings to reduce fire risk

In environments dominated by temperate forests and shrublands prone to crown-fires, increases in extreme heat and changed rainfall patterns are increasing the frequency and intensity of wildfires (McKenzie et al. 2016). Exposure of high value property, such as urban housing, to regular wildfires is acute in parts of the world such as southern California, Canada, southern Australia and southern Europe (Moritz et al. 2014). The challenge of coping with the increasing risk to people and property is compounded by ongoing urban expansion into areas of highly flammable vegetation (Bowman et al. 2017). 
Strategies to reduce fire risk can provide opportunities and choices for biodiversity within a renewal ecology framework. For example, treatment of fuel may be more effectively achieved through permanent modification of natural vegetation close to urban settlements, rather than using prescribed fire, which is both costly (Penman et al. 2013) and hazardous to the health of residents through exposure to smoke (Broome et al. 2016). Creation of linear parklands substituting low-for high-flammability vegetation (e.g. rainforest or Callitris spp. instead of Eucalyptus spp. in Australia) that separate wildland and urban areas may provide alternative habitats for species and amenity values for urban residents while at the same time reducing direct exposure of properties to fire risk. In particular, the opportunities to create a fine-scale mosaic of varied habitats may arise through deliberate plantings of vegetation less prone to propagation of crown fires and embers. This may enhance fine-scale diversity relative to simplification of native vegetation via mechanical clearing or other forms of repetitive fuel treatment, such as prescribed burning.

\section{Greening to cool cities and connect people to nature}

Globally, the number of people living in urban environments already exceeds those outside cities. By $2050,66 \%$ of the world's projected population of about 9.7 billion is expected to be urban (United Nations 2015). With rising temperatures, exacerbated by the urban heat island effect, the human population is expected to spend more time indoors in air-conditioned environments, increasing energy consumption and reducing connection with nature (Shanahan et al. 2014).

Application of renewal ecology concepts to urban environments starts with biodiversity-sensitive design, moving beyond existing approaches that focus on preserving remnants, to incorporating biodiversity into the urban fabric (Garrard et al. in review). Greening urban environments can generate physical and mental health benefits; reduce energy consumption by buffering microclimates and reduce the urban heat island effect; store carbon; alleviate the impacts of flooding by reducing peaks in storm water runoff; provide shelter from extreme weather; and contribute to biodiversity conservation, particularly threatened plant and animal species. The design elements that would characterize a renewal ecology approach to cities could include vegetated roofs and walls and purpose-designed and built structures that enable safe movements of animals across the landscape, reducing road-kill and the effects of habitat fragmentation (Laurance et al. 2014). Creating opportunities for urban residents to engage with nature where they live, work, play and travel can potentially be achieved through sensitive urban design that integrates both native and non-native plants and animals into courtyards, school yards, suburban gardens and transport corridors. 
Freshwater and coastal species are already among the most threatened as a consequence of their habitats being a focus of human settlements and livelihoods, and because global consumption of water is increasing with growing populations and greater wealth. Freshwater ecosystems are particularly vulnerable to human impacts from activities in water catchments, fragmentation of rivers by infrastructure, and from water consumption that alters the quality, quantity and timing of water flows (Pittock et al. 2015). All these effects are exacerbated by climate change. Many of the most serious impacts of climate change on people and biodiversity are felt via impacts on water, including floods, droughts, storms and changes in rainfall distribution (Bates et al. 2008). In addition to the direct impacts on biodiversity, many human responses to climate change will detrimentally affect aquatic ecosystems (Pittock 2015). These include mitigation measures that consume more water, such as many types of biofuel production, and adaptation measures, including increased storage of water in reservoirs.

A renewal ecology approach to water management would aim to meet human needs while sustaining aquatic biodiversity. There are a number of existing examples of interventions consistent with this philosophy that are currently implemented in an ad hoc manner. These include: environmental water releases that mimic pre-development river flows so as to conserve selected biodiversity; reserving aquatic refugia that also offer recreational opportunities; adding fish ladders to reservoirs to assist migration; systematically restoring riparian vegetation to cool rivers, reduce erosion and provide habitat and opportunities for recreation; and the removal of redundant dams. Integrated implementation of these established practices can enhance the catchment-scale functioning of aquatic systems and link urban, agricultural and natural areas.

\section{Biodiversity opportunities from changing agricultural practices}

Farmers are modifying agricultural landscapes to remain economically viable in a changing climate (Nelson et al. 2014). Relatively simple modifications include adopting land use practices that reduce water loss (e.g. conservation tillage); adopting geospatial precision farming technologies; and switching to more heat-tolerant livestock breeds. Where changing conditions make existing agricultural systems untenable, major modifications are leading to some agricultural systems being replaced, displaced or abandoned entirely (Rickards \& Howden 2012).

Adapting agricultural landscapes to climate change could potentially exacerbate their already substantial impacts on biodiversity (Maxwell et al. 2016). Adopting a renewal ecology approach to adaptation, however, could mitigate and potentially reverse some of these impacts. Heat stress in 
livestock can be mediated by establishing tree plantations alongside grazing areas, and biodiversity can benefit from such planting if they are made species-rich and permanent (Karki \& Goodman 2010). Shifts to grazing in regions where declining rainfall is making cropping unviable may offer opportunities for creation of critical habitat for threatened species, enhanced pollination and shelter services, and potentially pest, disease and weed management services. Finally, abandoned farmland offers opportunities to reconnect remnant vegetation or to recreate highly threatened ecosystem types, such as native grassland or grassy woodland (Ceausu et al. 2015; Middendorp et al. 2016).

Cohabitation of species and renewable energy sources

Almost all forms of power generation have the potential to harm biodiversity. For instance, poorly placed wind generators can harm fauna and unconventional (i.e. coal seam and shale) gas as a lower carbon 'transition fuel' could reduce biodiversity by increasing access to little developed regions, increasing habitat fragmentation and polluting freshwater ecosystems (Cook et al. 2013). Carbon capture and geological storage (Carter 2015), nuclear power, first generation biofuel crops, (CBD 2010; Dalla Marta et al. 2015) and solar thermal power stations (Pittock et al. 2013) all affect freshwater sources as does planting forests to mitigate emissions by increasing water consumption rates (Pittock et al. 2013). Hydropower dams also have severe impacts on freshwater ecosystems.

A renewal ecology approach adapts the design of the new systems to minimize losses and maximize opportunities. For example, the large areas of land and sea occupied by solar and wind generators offer opportunities for cohabitation with biodiversity, especially where the land has been degraded. In the sea, offshore wind and wave farms serve as de facto marine protected areas because trawl fishing, a major source of marine habitat degradation, is excluded (Ashley et al. 2014). The foundations of offshore energy harnessing infrastructure may be co-designed to serve as artificial reefs, or anchor points for aquaculture that might otherwise pollute habitats closer inshore (Buck et al. 2004).

\section{Creating positive legacies from abandoned mines}

Classically, the objective of post-mining rehabilitation has been to replace destroyed ecosystems, although this is rarely achieved (Bell 2001). By leveraging off the substantial financial resources and equipment available for mine site restoration programs, a renewal ecology approach would focus on the deliberate creation of novel ecosystems and landscapes designed to provide habitat and sanctuaries for both native and non-native threatened species (Harris et al. 2013). Examples of postmining land that have become biodiversity hotspots demonstrate that this approach is feasible. For instance, wetlands created from rehabilitated sand-mined areas have provided bird habitat in 
southwestern Western Australia (Brooks \& Nichols 1996) and the largest known breeding site for ghost bats in the Northern Territory, Australia (Woinarski et al. 2014).

\section{Conclusions}

Growing human populations and associated environmental impacts on the Earth system are driving ecological degradation and the ongoing extinction crisis. This presents profound challenges to the principles and practice of applied ecology, with growing acceptance that the future of biodiversity and the provision of ecosystem services will depend on more radical interventions than have been previously countenanced, including the intentional creation of novel ecosystems. Engineering and technological interventions have the potential either to exacerbate or mitigate ecosystem damage. We argue that ecologists must promote opportunities to integrate ecosystem processes and biodiversity into landscape-scale interventions, a concept we call 'renewal ecology'. We provide examples of this approach in the freshwater, marine and terrestrial environments.

In a period of rapid change all strategies carry risk of failure. We therefore see the potential of renewal ecology as being additional to existing conservation approaches rather than as a call to replace them. In this context, the concept espoused by Aplet and Gallo (2012) of a "portfolio approach" to nature conservation is pertinent. Such an approach across landscapes is based on different principles and practices ranging from the classic nature reserve to more innovative, experimental and historical approaches inherent in renewal ecology. This hedges against the failure of any particular approach to biodiversity protection and human wellbeing. Such plurality of approaches reduces rather than exacerbates philosophical tensions amongst conservation practitioners. Importantly renewal ecology can motivate other sectors in the economy to incorporate biodiversity into their current and future responses to climate change, thereby increasing the economic base and area for conservation (Rosenzweig 2003). In sum, renewal ecology is a project reconciling humans and nature, of co-creating a vibrant, diverse world for humans and other species. Though there will undoubtedly be missteps and mistakes along the way, this approach promises the possibility of a world that, while changed, is greener, wilder and happier than today. 


\section{References}

Arkema KK, Guannel G, Verutes G, Wood SA, Guerry A, Ruckelshaus M, Kareiva P, Lacayo M, Silver JM (2013) Coastal habitats shield people and property from sea-level rise and storms. Nature Climate Change 3:913-918

Ashley MC, Mangi SC, Rodwell LD (2014) The potential of offshore windfarms to act as marine protected areas-a systematic review of current evidence. Marine Policy 45:301-309

Barbier EB, Hacker SD, Kennedy C, Koch EW, Stier AC, Silliman BR (2011) The value of estuarine and coastal ecosystem services. Ecological Monographs 81:169-193

Bates BC, Kundzewicz ZW, Wu S, Palutikof JP (2008) Climate Change and Water. Technical Paper of the Intergovernmental Panel on Climate Change (IPCC). IPCC, Geneva

Bell LC (2001) Establishment of native ecosystems after mining - Australian experience across diverse biogeographic zones. Ecological Engineering 17:179-186

Bowman DMJS, Williamson GJ, Abatzoglou JT, Kolden CA, Cochrane MA, Smith AMS (2017) Human exposure and sensitivity to globally extreme wildfire events. Nature Ecology and Evolution 1: article 58

Brooks DR, Nicholls FM (1996) Environmental management and wetlands development at Capel in Southwest Western Australia. Pages 557-570 In: Mulligan DR (ed) Environmental Management in the Australian Minerals and Energy Industries: Principles and Practice. University of New South Wales Press, Sydney

Broome RA, Johnston FH, Horsley J, Morgan GG (2016) A rapid assessment of the impact of hazard reduction burning around Sydney, May 2016. Medical Journal of Australia 205:407-408

Buck BH, Krause G, Rosenthal H (2004) Extensive open ocean aquaculture development within wind farms in Germany: the prospect of offshore co-management and legal constraints. Ocean \& Coastal Management 47:95-122

Bulleri F, Chapman MG (2010) The introduction of coastal infrastructure as a driver of change in marine environments. Journal of Applied Ecology 47:26-35

CBD (2010) X/37. Biofuels and biodiversity. UNEP/CBD/COP/DEC/X/37. Convention on Biological Diversity, Montreal 
Ceausu S, Hofmann M, Navarro LM, Carver S, Verburg PH, Pereira HM (2015) Mapping opportunities and challenges for rewilding in Europe. Conservation Biology 29:1017-1027

Chazdon RL, Laestadius L (2016) Forest and landscape restoration: toward a shared vision and vocabulary. American Journal of Botany 103:1869-1871

Cook P, Beck V, Brereton D, Clark R, Fisher B, Kentish S, et al. (2013) Engineering energy: unconventional gas production. Australian Council of Learned Academies, Melbourne

Dalla Marta A, Orlando F, Mancici M, Orlandini S (2015) Water and biofuels. Pages 108-122 In: Pittock J, Hussey K, Dovers S (eds) Climate, energy and water. Cambridge University Press, Cambridge Hagerman SM, Satterfield T (2014) Agreed but not preferred: expert views on taboo options for biodiversity conservation, given climate change. Ecological Applications 24:548-559

Harris S, Arnall S, Byrne M, Coates D, Garnett ST, Hayward M, Martin T, Mitchell N (2013) Whose backyard? Choosing sites for assisted colonisation. Ecosystem Management and Restoration 14:106111

Head L (2016) Hope and Grief in the Anthropocene: re-conceptualising Human-Nature Relations. Routledge, New York

Higgs E (2003) Nature by Design: People, Natural Process, and Ecological Restoration. MIT Press, Cambridge, Massachusetts

Hobbs RJ, Arico S, Aronson J, Baron JS, Bridgewater P, Cramer VA, Epstein PR, Ewel JJ, et al. (2006) Novel ecosystems: theoretical and management aspects of the new ecological world order. Global Ecology and Biogeography 15:1-7

Hobbs RJ, Hallett LM, Ehrlich PR, Mooney HA (2011) Intervention ecology: applying ecological science in the twenty-first century. BioScience 61:442-450

Kareiva P, Fuller E (2016) Beyond resilience: how to better prepare for the profound disruption of the Anthropocene. Global Policy 7:107-118

Laurance WF, Clements GR, Slan S, O'Connell CS, Mueller ND, Goosem M, Venter O, Edwards DP, Phalan B, Balmford A, Van Der Ree R, Arrea IB (2014) A global strategy for road building. Nature 513:229-232 
Martin LJ, Quinn JE, Ellis EC, Shaw MR, Dorning MA, Hallett LM, Heller NE, Hobbs RJ, Kraft CE, Law E, Michel NL (2014) Biodiversity conservation opportunities across the world's anthromes. Diversity and Distributions 20:745-755

Maxwell S, Fuller R, Brooks T, Watson J (2016) Biodiversity: the ravages of guns, nets and bulldozers. Nature 536:143

Maxwell S, Venter O, Jones KR, Watson, JEM (2015) Integrating human responses to climate change into conservation vulnerability assessments and adaptation planning. Annals of the New York Academy of Sciences 1355:98-116

McKenzie D, Littell J (2016) Climate change and the eco-hydrology of fire: will area burned increase in a warming western U.S.? Ecological Applications, published online, doi:10.1002/eap.1420

Middendorp, RS, Perez AJ, Molina A, Lambin, EF (2016) The potential to restore native woody plant richness and composition in a reforesting landscape: a modeling approach in the Ecuadorian Andes. Landscape Ecology 31:1581-1599

Moritz MA, Batllori E, Bradstock RA, Gill AM, Handmer J, Hessburg PF, Leonard J, McCaffrey S, Odion DC, Schoennagel T, Syphard AS (2014) Learning to Coexist with Wildfire. Nature 515:58-66

Murcia C, Aronson J, Kattan GH, Moreno-Mateos D, Dixon K, Simberloff D (2014) A critique of the 'novel ecosystem'concept. Trends in Ecology \& Evolution 29:48-53

Myers N (1993) Biodiversity and the precautionary principle. Ambio 22:74-79

Nelson GC, Valin H, Sands RD, Havlík P, Ahammad H, Deryng D, et al. (2014) Climate change effects on agriculture: economic responses to biophysical shocks. Proceedings of the National Academy of Sciences 111:3274-3279

Penman TD, Bradstock RA, Price OF (2013) Reducing wildfire risk to urban developments: simulation of cost-effective fuel treatment solutions in south eastern Australia. Environmental Modelling and Software 52:166-175

Perrings C, Jackson L, Bawa K, Brussaard L, Brush S, Gavin T, Papa R, Pascual U, De Ruiter P (2006) Biodiversity in agricultural landscapes: saving natural capital without losing interest. Conservation Biology 20:263-264 
Pittock J (2015) Biodiversity and the climate, energy and water nexus. Pages 283-302 In: Pittock J, Hussey K, Dovers S (eds) Climate, energy and water. Cambridge University Press, Cambridge

Pittock J, Finlayson M, Arthington AH, Roux D, Matthews JH, Biggs H, et al. (2015) Managing freshwater, river, wetland and estuarine protected areas. Pages 569-608 In: Worboys GL, Lockwood M, Kothari A, Feary S and Pulsford I (eds) Protected area governance and management. ANU Press, Canberra

Pittock J, Hussey, K, McGlennon S (2013) Australian Climate, Energy and Water Policies: conflicts and synergies. Australian Geographer 44:3-22.

Ricciardi A, Simberloff D (2009) Assisted colonization is not a viable conservation strategy. Trends in Ecology \& Evolution 24:248-253

Rickards L, Howden SM (2012) Transformational adaptation: agriculture and climate change. Crop Pasture Science 63:240-250

RohwerY, Marris E (2016) Renaming restoration: conceptualizing and justifying the activity as a restoration of lost moral value rather than a return to a previous state. Restoration Ecology 24:674679

Shanahan DF, Lin BB, Gaston KJ, Bush R, Fuller RA (2014) Socio-economic inequalities in access to nature on public and private lands: a case study from Brisbane, Australia. Landscape and Urban Planning 130:14-23

Scheffers BR, De Meester L, Bridge TCL, Hoffmann AA, Pandolfi JM, Corlett RT, Butchart AHM, PearceKelly P, Kovacs KM, Dudgeon D, et al. (2016) The broad footprint of climate change from genes to biomes to people. Science 354: doi: 10.1126/science.aaf7671

Steffen W, Crutzen PJ, McNeill JR (2007) The Anthropocene: are humans now overwhelming the great forces of nature. Ambio 36:614-621

Stott P (1998) Editorial: biogeography and ecology in crisis: the urgent need for a new metalanguage. Journal of Biogeography 25:1-2

Syphard A, Butsic V, Bar-Massada A, Keeley J, Tracey J, Fisher R (2016) Setting priorities for private land conservation in fire-prone landscapes: are fire risk reduction and biodiversity conservation competing or compatible objectives? Ecology \& Society 21: article 2 
United Nations (2015) World Population Prospects: the 2015 revision: key findings and advance tables. Department of Economic and Social Affairs, Population Division. United Nations, New York

Woinarski JCZ, Burbidge, AA, Harrison, PL (2014) The Action Plan for Australian Mammals 2012. CSIRO Publishing, Canberra

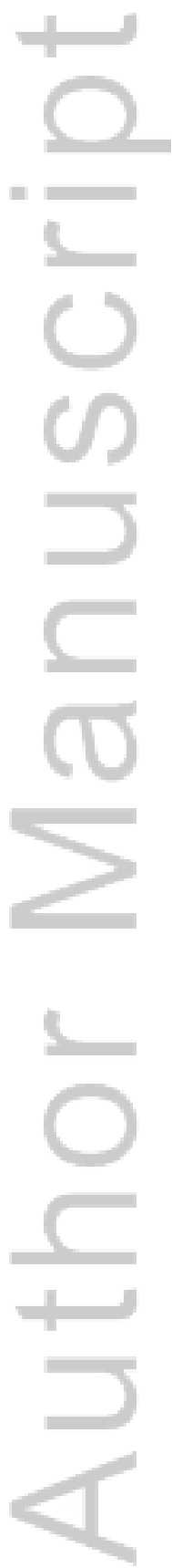

This article is protected by copyright. All rights reserved. 


\section{Box 1: Definition of Renewal Ecology and its relationship to related disciplines}

There is increasing recognition that classical approaches to conservation and natural resources management are unable to meet the challenges of the Anthropocene. Martin et al. (2014) provide a valuable summary (their Table 1) of how existing scientific fields, and proposed new ones, and associated concepts can contribute to conservation goals and human livelihoods in the face of global environmental change. Our concept of renewal ecology, defined as "a solutions-focused discipline aimed at creating and managing ecosystems designed to maximize both biodiversity and human wellbeing in the face of rapid environmental change" builds on these approaches, and below we briefly outline (in alphabetical order) how renewal ecology differs or enhances some key related fields and concepts.

Agroecology: Renewal ecology incorporates the argument of Perrings et al. (2006) that understanding agriculture as an ecological system, where biodiversity plays a critical beneficial role for food production and provision of ecosystems, is essential given increasing conversion of wildland to agriculture to feed increasing human populations.

Compassionate conservation: an approach to management of trophic interactions to reduce the need for lethal control to stabilise wildlife and pest species (Ramp \& Bekoff 2015). Such ethical consideration of the treatment of the non-human world is shared in renewal ecology.

Conservation biology: aimed at reducing the risk of extinction of non-human species and degradation of their habitats and the services they provide, taking past abundance, composition and/or structure as an aspirational standard. We propose renewal ecology as more forward-looking than traditional conservation biology, focusing on adaptation opportunities that provide benefits for biodiversity while people directly or indirectly adapt to global change.

Conservation science: proposed by Kareiva and Marvier (2012) to make conservation biology more responsive and relevant to current threats through the 'application of both natural and social sciences to the dynamics of coupled human-natural systems'. They argue that human well-being and social justice must be central to all conservation efforts with a focus on provision of ecosystems services, an ethos central to renewal ecology.

\section{Human ecology/Coupled human-natural systems/Social-ecological systems (herein termed 'human} ecology'): the interdisciplinary and trans-disciplinary study of the relationship between humans and their natural and built environments. In clearly defined and data-rich systems, methodologies developed in human ecology can be employed to evaluate likely biodiversity and human benefits 
associated with alternative renewal ecology interventions. Such holistic understanding of human nature coupling is fundamental to the practice of renewal ecology.

Intervention ecology: Hobbs et al. (2011) outlined the case for steering restoration ecology and land management towards a more 'thoughtful experimental approach embedded in adaptive management' and have suggested the term 'intervention ecology' to capture approach. Renewal ecology builds on this argument by focusing on the need to design ecosystems consciously and manage them actively, using targeted interventions in the face of unprecedented environmental change.

Novel ecosystems: the concept that new assemblages of species (i.e. those that have no historical precedent) will result from differential responses to global change (Hobbs et al. 2006). These assemblages may be biodiverse, functional, resilient, and self-sustaining. Renewal ecology is aimed at managing the trajectory of such novel assemblages to maximize biodiversity and services.

Precautionary principle and biodiversity: The principle of 'do no harm' and placing the 'burden of proof' on proponents of environmental change lie at the heart of the precautionary principle. But an overly cautious approach to undertaking active interventions to save species can, in itself, contribute to extinction risk (Myers 1993). Renewal ecology argues for bet-hedging, rather than risk aversion inherent in 'intervention ecology' (see above).

Reconciliation ecology: Rosenzweig (2003) presciently recognized that effort should be made to modify diverse anthropogenic landscapes to create habitat for species, thereby increasing biodiversity. Renewal ecology embraces this idea but, because of the pervasive effects of global environmental change, applies it to all natural systems.

Restoration ecology: has generally been aimed at assisting the recovery of ecosystems that have been degraded or destroyed to return to a previous, indigenous, state. Renewal ecology recognizes that in many cases, the rapidity of environmental change means that such an objective is unlikely to be achieved and instead promotes the creation and/or enhancement of landscapes that support biodiversity and provide ecosystem services for human communities in the context of change.

Urban ecology: the study of the relationships and interactions between all organisms - human and non-human - within this most anthropogenic of landscapes. This discipline can be regarded as a fundamental component of renewal ecology. 


\section{University Library}

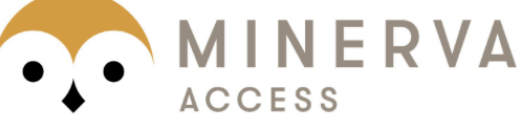

A gateway to Melbourne's research publications

Minerva Access is the Institutional Repository of The University of Melbourne

\section{Author/s:}

Bowman, DMJS;Garnett, ST;Barlow, S;Bekessy, SA;Bellairs, SM;Bishop, MJ;Bradstock, RA;Jones, DN;Maxwell, SL;Pittock, J;Toral-Granda, MV;Watson, JEM;Wilson, T;Zander, KK;Hughes, L

Title:

Renewal ecology: conservation for the Anthropocene

Date:

2017-09-01

\section{Citation:}

Bowman, D. M. J. S., Garnett, S. T., Barlow, S., Bekessy, S. A., Bellairs, S. M., Bishop, M. J., Bradstock, R. A., Jones, D. N., Maxwell, S. L., Pittock, J., Toral-Granda, M. V., Watson, J. E. M., Wilson, T., Zander, K. K. \& Hughes, L. (2017). Renewal ecology: conservation for the Anthropocene. RESTORATION ECOLOGY, 25 (5), pp.674-680. https://doi.org/10.1111/ rec. 12560 .

Persistent Link:

http://hdl.handle.net/11343/293344 